\title{
Efficiency of hanging silt curtains in cross-flow
}

Max Radermacher ${ }^{1}$, Lynyrd de Wit $^{2}$, Johan C. Winterwerp ${ }^{3}$, Wim S.J. Uijttewaal ${ }^{4}$

\begin{abstract}
When dredging in sensitive environments, efforts have to be made to limit the free dispersal of suspended fine sediment from the dredging spill. Especially the use of hanging silt curtains as an environmental mitigation measure is widespread. Despite frequent application, their ability to reduce turbidity levels through vertical diversion of sediment-laden currents remains subject of debate. This paper addresses a series of laboratory measurements and numerical model simulations in order to determine the efficiency of hanging silt curtains, defining a new efficiency parameter. The model was validated against the laboratory experiments. Model simulations focusing on vertical diversion of the sediment-laden current suggest that hanging silt curtains do not have a favorable influence on the settling of suspended sediment when applied in cross-flow. Diversion of currents underneath the curtain causes flow separation and intense turbulent mixing, which counteracts settling of suspended sediment particles. The results imply that the widespread application of hanging silt curtains should be reconsidered from a physical point of view.
\end{abstract}

ASCE Subject headings: Dredging, Turbidity, Environmental issues, Turbulence, Numerical models, Laboratory tests

\footnotetext{
${ }^{1}$ Ph.D. Student, Delft Univ. of Technology, Faculty of Civil Engineering and Geosciences, Stevinweg 1, 2628CN Delft, The Netherlands (corresponding author). E-mail: m.radermacher@tudelft.nl.

${ }^{2}$ Fluid Mechanics Expert, Svasek Hydraulics, Schiehaven 13G, 3024EC Rotterdam, The Netherlands.

${ }^{3}$ Professor of Sediment Dynamics, Delft Univ. of Technology, Faculty of Civil Engineering and Geosciences; and Senior Expert, Deltares, Rotterdamseweg 185, 2629HD, Delft, The Netherlands.

${ }^{4}$ Professor of Experimental Hydraulics, Delft Univ. of Technology, Faculty of Civil Engineering and Geosciences, Stevinweg 1, 2628CN Delft, The Netherlands.
} 
2 During several stages of a dredging cycle, fine sediment may be released in the water column.

3 Owing to its low settling velocity, fine sediment can stay in suspension for long periods of 4 time. The resulting turbidity clouds, subject to ambient currents, are transported away from the dredging site. This elevated turbidity may have an adverse effect on primary production rates and various vulnerable marine species, corals and sea grasses being notorious examples (Bray 2008; Erftemeijer and Robin Lewis 2006; Erftemeijer et al. 2012). Shading (i.e. attenuation of daylight) and burial are the main processes responsible for this possible environmental impact.

In order to protect the marine environment, dredging contractors and their clients take environmental mitigation measures when necessary. Application of silt curtains is often regarded an efficient way to avoid dispersal of suspended fine sediment. Silt curtains are flexible barriers, deployed between the source of turbidity and a sensitive receptor. They come in two basic types, being the hanging and the standing type, see Figure 1. Hanging silt curtains consist of a series of floaters on the water surface and a flexible cloth, which is kept more or less vertical by heavy chains. A gap is maintained near the bed to account for tidal modulation and pressure release in case of cross currents, which also leads to flaring of the curtain. At many dredging projects worldwide, hanging silt curtains are placed in cross-flow. In that case, the intended working principle of the curtain is to divert the current vertically through the gap between the curtain and the bed. This is assumed to reduce the settling time of suspended sediment which is transported with the cross-flow, diverting the current towards the bed. Standing curtains are attached to a heavy sinker pipe near the bed and a series of floaters on the free surface, typically covering the full water depth. Because a pressure release 
mechanism is lacking, standing curtains are more sensitive to mechanical failure when placed in a cross-flow. Hence, their intended working principle differs from that of hanging silt curtains. Standing curtains are generally used to separate the source area of turbidity from the main flow and create a calm zone, which is not always feasible, depending on the intensity of environmental conditions. Furthermore, they require heavy floating equipment for (re)placement. As a result, many dredging contractors have a preference for the hanging type. In this paper, the focus is on hanging silt curtains in cross-flow. Also, the case of applying silt curtains directly in front of a sensitive receptor, so as to guide suspended sediment away from the sensitive environment, is disregarded in this study.

Silt curtains can be placed in various configurations, depending on the requirements and constraints of the dredging project (Francingues and Palermo 2005). The schematic in Figure 2 shows two representative configurations for hanging silt curtains. Configuration (a), the open configuration, is typically applied at some distance from the shore, when the spatial scale of the dredging site is large and accessibility must be guaranteed. Configuration (b) is situated at the open end of a semi-enclosed reclamation area.

This paper assesses the efficiency of hanging silt curtains when subject to an ambient cross current of arbitrary, but significant flow velocity. That situation applies for example to configuration (a), but also to configuration (b) in case of an ebb-tidal current or a wind-driven current when the semi-enclosed basin is of considerable size. In this study, the case of crossflow passing a hanging silt curtain is treated as a two-dimensional vertical (2DV) flow problem in a transect perpendicular to the curtain. By doing so, lateral effects like horizontal diversion of flow are ignored. The consequences of this approach are limited and do not 
obscure the analysis of silt curtain effectiveness, as treated in further detail in the discussion section.

Hanging silt curtains are supposed to divert sediment-laden currents towards the bed, thereby reducing the time to settle from the water column and the horizontal range of influence of the suspended sediment. However, based on practical experience, questions have been raised on the efficiency of hanging silt curtains (Francingues and Palermo 2005, Vu and Tan 2010, Ogilvie et al. 2012). In particular, vertical mixing downstream of the silt curtain is often observed to counteract the settling induced by the curtain.

Scientific research into silt curtain efficiency, as published in literature, has not addressed the topic to its full extent yet. The main focus has been on mechanical and practical aspects of silt curtains (JBF Scientific Corporation 1978; Francingues and Palermo 2005; Ogilvie et al. 2012). The efficiency of silt curtains as an environmental mitigation measure has been treated by Yasui et al. (1999), Jin et al. (2003), Vu et al. (2010), Vu and Tan (2013) and Wang et al. (2015), based on laboratory experiments and measurements in the field. The painstaking nature of such physical model tests has inhibited rigid conclusions regarding the effect of silt curtains on the reduction of turbidity under various relevant conditions. Hanging silt curtain efficiency reported from field measurements varies from slightly favorable (Vu et al. 2010) to explicitly unfavorable (Jin et al. 2003), based on sparse measurements. The complexity of the flow field around a silt curtain and the use of different measurement locations and analysis methods hamper interpretation and comparison of the results. Therefore a combination of laboratory tests and advanced numerical modeling seems attractive.

This study aims at assessing the efficiency of silt curtains under the relevant range of flow conditions one may encounter in cases of silt curtain application. To this end, use is made of 
numerical model simulations, which yields an extensive dataset suitable for sensitivity analysis. Validation of the numerical model results is done by comparing to physical model experiments. Both models and their comparison are described in the modeling section, including upscaling of the numerical model from laboratory scale to full scale. Subsequently, the parameters which should be used to quantify the efficiency of silt curtains are introduced. In the results section, the results of the numerical model simulations, including suspended sediment transport, are presented and silt curtain efficiency is evaluated. Some additional aspects of the results are treated in the discussion section, followed by the conclusions.

\section{Modeling}

The turbulent flow field and sediment concentrations around a silt curtain were assessed using a laterally non-varying approach. In the 3D physical and numerical models which were employed, the silt curtain covered the full width. Lateral diversion of flow around the edges of a silt curtain is not possible with this approach, hence the full fine sediment flux is forced to pass underneath the curtain. The implications of this choice are discussed in further detail in the discussion section. A numerical model, based on Large Eddy Simulation, was used to assess the efficiency of silt curtains at full scale. First, the model setup is treated. Physical experiments in a laboratory flume were conducted to validate the computed turbulent flow field at laboratory scale, at Froude numbers which are close to realistic conditions in the field. Next, the experimental setup and visual observations of the flow field are described and finally the validation is presented. 
In the flow field around a silt curtain, flow separation and turbulent mixing play a prominent role. Reliable results are only expected when the turbulent flow field is (partly) resolved, which is done in this study through the application of Large Eddy Simulation (LES). In this type of turbulence modeling, turbulent fluctuations are averaged over every numerical grid cell (i.e. averaged in space), in contrast to the more conventional Reynolds averaged (i.e. ensemble averaged) approach. LES allows turbulent vortices to develop down to the scale of the computational mesh size. At the upstream boundary, turbulent eddies were seeded through the use of the synthetic eddy method (SEM; Jarrin et al. 2006). The time-averaged flow velocity profile at the upstream boundary was logarithmic.

Although the flow problem assessed in this laterally non-varying approach is essentially 2DV, the application of LES made a 3D model domain necessary. Turbulence behaves fundamentally different in a 2DV domain than in a 3D domain, as vortex stretching cannot be accounted for adequately in two dimensions (e.g. Kraichnan and Montgomery 1980). Hence a third dimension was added to the numerical model domain, with a length scale similar to the water depth. The computational grid consisted of 450x40x40 cells in the $x, y$ and $z$ direction respectively. The silt curtain covered the full width of the domain and was represented as a vertical, stiff and straight baffle, see Figure 3. The actual, flared shape of the curtain as encountered in reality was not included in the model directly, although the height of the baffle was adjusted to the effective height after flaring as measured in the laboratory. At sub-grid level, turbulent diffusion was represented by the wall-adapting local eddy-viscosity (WALE) model (Nicoud and Ducros 1999). Erosion of the bed was not included in the model, 
as to avoid confusion of different processes influencing turbidity levels around the silt curtain.

114 A detailed description of the model is included in the appendix.

117 Validation of these turbulent flow simulations requires high-frequency velocity measurements 118 in a laboratory flume. To this end, Laser Doppler Anemometry (LDA) was applied in the 119 laboratory set-up presented in Figure 4. The flow velocity was sampled at $100 \mathrm{~Hz}$ for $200 \mathrm{~s}$ in 120 a 6 x 19 grid ( $x$ and $y$ directions respectively) downstream of a silt curtain scale model. The 121 flume had a width of $0.40 \mathrm{~m}$ and a length of $14 \mathrm{~m}$. The discharge was controlled by a valve in 122 the supply pipe and measured by means of a digital flow meter. The water depth was controlled by a weir at the downstream end of the flume, and was kept fixed at $0.35 \mathrm{~m}$.

124 The physical experiment covered a series of six different conditions, varying both the relative 125 silt curtain height $h_{\text {rel }}$ and the Froude number $F$, see equations 1 and 2. Here, $h_{s}$ is the 126 effective silt curtain height after flaring (see Figure 5), $h$ represents the water depth, $U$ 127 represents the depth-averaged flow velocity along the $x$-coordinate and $g$ denotes the 128 gravitational acceleration.

$$
h_{r e l}=\frac{h_{s}}{h}
$$

$$
F=\frac{U}{\sqrt{g h}}
$$

$$
R=\frac{U h}{v}
$$


Values of $F$, ranging from 0.029 to 0.071 , were chosen for representing realistic conditions in the field ( $h=5 \mathrm{~m}$ and $U=0.2-0.5 \mathrm{~m} / \mathrm{s}$ ). As a result, the Reynolds number $R$ (see equation 3, where $v$ is the kinematic viscosity) attained significantly lower values in the laboratory $\left(1.7 \cdot 10^{4}-4.2 \cdot 10^{4}\right)$ than in the field $\left(9.1 \cdot 10^{5}-2.3 \cdot 10^{6}\right)$. However, these Reynolds numbers fall within the turbulent regime. Combined with the strong silt curtaininduced flow disturbance, turbulent flow should fully develop at laboratory scale.

During the physical experiments, use was made of a flexible silt curtain with weights attached at its lower edge. As in reality, this led to flaring of the silt curtain when exposed to a cross current. A weighting of $1.24 \mathrm{~kg} / \mathrm{m}$ was chosen in order to achieve realistic curtain deformations under the tested range of Froude numbers. Before flaring, the two different curtains applied in the experiments had relative curtain heights of 0.5 and 0.75 (i.e. the curtains covered $50 \%$ and $75 \%$ of the water depth, respectively). The relative curtain height after flaring was variable, depending on the flow rate in the flume and the associated deformation of the curtain. The silt curtain scale model was constructed from a flexible, densely woven fabric. No attention was paid to details of the fabric's permeability, but visualizations with dye showed that virtually no water passed through the fabric. The gap between the curtain and the bed provides a far more effective pressure release in case of a cross current than possible permeability of the fabric would. The flow, seeking for the path of least resistance, passes underneath the curtain rather than through. This effect was verified using dye injections and is expected to occur in the field as well. Clogging of the fabric and marine growth on the silt curtain add to this behavior.

The turbulent flow field observed in the laboratory was visualized with dye, see Figure 5 . The curtain causes flow separation, leading to wake formation and strong production of 
turbulence. Vortices grow from the curtain's lower edge and transport dye upward. Most of the dye is advected downstream with the main flow, but part of the dye gets trapped in the wake and is gradually reintroduced in the main flow. Although turbulent mixing appears to be less intense for lower $F$ and $h_{\text {rel }}$, the flow field described above remains qualitatively the same for all configurations.

\section{Validation of numerical model}

Two steps are presented to arrive at a suitable full scale numerical model. First, flow parameters as computed with a laboratory-scale numerical model are validated by comparing them to flow parameters which were measured during the laboratory experiment, using the same boundary conditions. The second step comprises of comparing full scale computations to laboratory scale computations.

Figure 6 shows computed and measured time-averaged horizontal and vertical flow velocities along the central axis of the model domain for $h_{\text {rel }}=0.5$ and $F=0.043$ as an example. Similar results and performance are found for all other tested configurations. The profiles of time-averaged horizontal flow velocity $\bar{u}$ show a near-bed jet flow induced underneath the silt curtain. Flow separation leads to the formation of a recirculation zone in the upper half of the water column, indicated in the upper panel. The dashed line marks the region where the time-averaged horizontal flow velocity integrates to zero along the vertical dimension, i.e. the mean dividing streamline. Further downstream, the jet flow spreads over the full water depth, which is associated with a redistribution of momentum through upward mean flow velocities (positive $\bar{w}$ ) in this region. Generally, the numerical model closely follows the laboratory 
experiments, given root-mean-square (RMS) errors of 5\% for the horizontal velocity and 25\% for the vertical velocity, relative to the maximum value measured in the second vertical profile $(x=0.4 \mathrm{~m})$.

A comparison of turbulence parameters is presented in Figure 7. Turbulence intensity is defined here as the standard deviation of the velocity time series. Flow separation near the lower edge of the silt curtain causes peak values of all turbulence parameters in this region, which diffuse over the full water column further downstream. The Reynolds shear stress $\tau_{u w}$, shown in the lower panel, is a measure for turbulent transport of dissolved or suspended matter. These profiles express intense turbulent mixing along the wake induced by the silt curtain. The performance of the LES model is good, as RMS errors remain very small (11\% for horizontal turbulence intensity $r_{u}, 11 \%$ for vertical turbulence intensity $r_{w}$ and $10 \%$ for $\tau_{u w}$, relative to the maximum values measured in the second vertical profile).

Next to this sequence of vertical profiles of flow parameters, the laboratory and numerical results are compared in the frequency domain. Figure 8 shows the one-dimensional frequency spectra of turbulent kinetic energy as derived for the experiment presented in Figures 6 and 7 ( $h_{\text {rel }}=0.5$ and $F=0.043$ ) at half depth and 3.5h downstream of the silt curtain. The figure also distinguishes between the macro scale and the inertial range with a $f^{-5 / 3}$ scaling (Pope 2000). An important requirement for the LES approach to be valid, is isotropy of turbulence at the sub-grid scales. This requirement appears to be fulfilled, since the spectrum derived from the numerical model partly covers the inertial range before being cut off by mesh size limitations at higher frequencies. 
Hence, it can be concluded that the ability of the LES model to simulate the flow field around a silt curtain has been demonstrated at laboratory-scale $(h=0.35 \mathrm{~m})$. However, silt curtain efficiency is determined from numerical simulations at full scale $(h=5 \mathrm{~m})$. The flow field is dominated by free turbulence, as a result of flow separation at the tip of the silt curtain. Such a flow field is known to depict self-similarity when scaled with $F$ and the governing geometric parameter (in this case $h_{r e l}$ ), while hardly depending on the Reynolds number. Therefore, the profiles of flow and turbulence parameters for full scale simulations are similar to those shown in Figures 6 and 7, with peak values at the same relative depth $(z / h)$, but of different magnitude, depending on the Froude-scaling. Hence, it is argued that upscaling of the model results to realistic length scales does not introduce any significant error.

It was indicated that the curtain is represented in the numerical model as a vertical, straight baffle, without the possibility to deform under influence of a cross current, but with the correct curtain height after flaring. However, through the formation of an eddy near the surface upstream of the baffle (see Vu and Tan, 2010), the main flow attains a shape as if it were deflected by a flared silt curtain. The orientation of the streamlines around the tip of the curtain in the numerical model closely resembles those in the physical model. This makes the amount of flow contraction in the jet flow very similar for both models. Hence, from the positive validation presented in this section, the consequences of this simplification appear to be limited, although it might explain the occurrence of some small deviations.

Silt curtain efficiency is determined from suspended load transport calculations of fine sediment. Down to the mesh size, advection of suspended sediment by turbulent motions (i.e. turbulent diffusion) is captured by the LES approach. The sub-grid-scale diffusion coefficient $\Gamma$ is obtained from the eddy viscosity $v_{e}$ by dividing the latter by the turbulent Prandtl- 
Schmidt number, Sc . Antonopoulos-Domis (1981) demonstrates that $S c=0.5$ is appropriate for fitting LES computations to laboratory data of isotropic turbulence. This finding is adopted here. Moreover, we found that the sensitivity of the advection-dominated LES model

to $S c$ is very small (differences in suspended sediment concentrations for model simulations with $S c=0.4$ and $S c=1.0$ are generally very small throughout the whole domain; the maximum deviation computed is $1 \%$ of the uniform concentration at model inflow). This provides further proof of the fact that sub-grid diffusion only has minor influence on sediment transport in the present model and that this model therefore is well capable of resolving turbulent mixing around the silt curtain. The suspended sediment concentrations used in this study $(<100 \mathrm{mg} / \mathrm{L}$ ) are far too low to have an influence on hydrodynamics through e.g. density differences (Whitehouse et al., 2000). Further validation of the suspended sediment transport model has been carried out by De Wit (2015).

\section{Efficiency parameters}

Before the model results can be discussed, appropriate parameters should be defined for quantification of silt curtain efficiency. Various authors have proposed a comparison of representative downstream and upstream values of suspended sediment concentration $C$ for this purpose (JBF Scientific Corporation 1978; Francingues and Palermo 2005; Vu et al. 2010; Ogilvie et al. 2012). This approach is disputable because of two reasons. First, $C$ does not fully express the possible environmental impact posed by turbidity. In general, suspended particles near the water surface have a much larger settling time than suspended particles near the bed, and can therefore be transported further away from the source (in this case the dredging site). Moreover, particles near the surface have a larger influence on the light 
climate in the water column than particles near the bed. Second, comparing downstream values to upstream values does not only express the influence of the silt curtain on turbidity values. It also reflects 'undisturbed' settling of the sediment between the two locations, defined here as settling of individual particles under influence of their settling velocity rather than downward advection by the flow. Especially for relatively coarse sediment and low ambient flow velocities, this must play a significant role.

The first problem is resolved by introducing an environmental impact potential $P$, as defined in equation 4, in which lateral variations ( $y$ coordinate) are neglected. The linear dependency on $C$ in this equation can be justified with data from Erftemeijer and Robin-Lewis (2006) and Erftemeijer et al. (2012), which show an approximately linear relation between suspended sediment concentrations and the environmental damage done to exposed corals and sea grasses, respectively. The influence of the vertical concentration distribution is incorporated by multiplying $C$ with the vertical coordinate $z$. With $z=0$ at the bed, the highest impact potential is assigned to suspended sediment near the free surface. Integration over the water column results in a longitudinal distribution of the environmental impact potential $P$, which is essentially the first moment of the vertical concentration distribution.

$$
P(x)=\int_{0}^{1} Z_{*} C_{*}(\mathrm{x}, \mathrm{z}) \mathrm{d} z_{*}
$$

with:

$$
Z_{*}=\frac{Z}{h}
$$

$$
C_{*}(x, z)=\frac{C(x, z)}{C_{\max }}
$$


Here, $z$ and $C$ are made dimensionless with the water depth $h$ and the maximum concentration at model inflow $C_{\max }$, yielding $Z_{*}$ and $C_{*}$.

The second problem is resolved by introducing an efficiency parameter, expressing the reduction in $P$. As mentioned before, several authors have compared downstream values to upstream (i.e. at inflow of the model domain) values. This yields the gross silt curtain efficiency $E_{S}$ as defined in equation 5, whereas we prefer to use the environmental impact potential $P$, instead of $C$.

$$
E_{S}(x)=\frac{P_{i n}-P(x)}{P_{\text {in }}} \cdot 100 \%
$$

As discussed, undisturbed settling of suspended sediment, which would also occur in conditions without a silt curtain, should be excluded from the efficiency parameter. This can be done through a reduction accounting for the settling of particles without a curtain. Thus, the reference value $P_{r e f}(x)$ is obtained from a reference simulation without a silt curtain, which is substituted into equation 5 to obtain the reference efficiency $E_{r e f}(x)$. Reduction of $E_{S}(x)$ with $E_{\text {ref }}(x)$ yields the net silt curtain efficiency $E_{\text {net }}(x)$, see equation 6 .

$$
E_{\text {net }}(x)=E_{S}(x)-E_{\text {ref }}(x)=\frac{P_{\text {ref }}(x)-P(x)}{P_{\text {in }}} \cdot 100 \%
$$

The difference between both parameters is illustrated with the conceptual example in Figure 9. This figure shows an initially depth-uniform concentration field in a flow with (upper panel) and without (lower panel) a silt curtain. Initially, the silt curtain brings the suspended sediment closer to the bed. However, strong turbulent mixing in the wake induces an upward flux of sediment, re-establishing the approximately uniform concentration profile over depth. 
In the flow field without a silt curtain, persistent settling gradually brings the sediment grains towards the bed. Values of $P$, indicated above every concentration profile in this figure, show that the silt curtain achieves a 30\% reduction in the environmental impact potential (i.e. from $P=0.5$ to $P=0.34)$. In the conventional view of silt curtain efficiency, the curtain has a favorable influence on turbidity levels, which is reflected by the gross efficiency: $E_{S}=32 \%$. However, if the curtain is absent, the reduction of $P$ is about $40 \%$, as a result of undisturbed settling. Hence the net effect of the curtain is unfavorable, which is reflected by the net efficiency: $E_{\text {net }}=-10 \%$. This example expresses the difference between both efficiency parameters. $E_{S}$ represents the combined effect of the silt curtain and undisturbed settling, whereas $E_{\text {net }}$ merely contains the effect of the curtain.

In this study, $x=10 h_{s}$ was adopted as the distance downstream from the curtain where $P$ and the efficiency parameters are evaluated. The region immediately downstream of the curtain is dominated by turbulent mixing, whereas settling of the sediment gradually takes over further downstream. The horizontal extent of the recirculation zone is found to be between 6 and 7 times the silt curtain height in our simulations. In order to evaluate silt curtain efficiency at the same position relative to the flow field in every simulation, $h_{s}$ is used to determine the evaluation coordinate. The position where vertical flow profiles reach their undisturbed values again is situated much further downstream, outside the model domain. To be as close as possible to this location, the maximum multiple of $h_{s}$ that fits inside the model domain for all simulations was chosen, being $x=10 h_{s}$. Further downstream (i.e. outside the model domain), the presence of the curtain will mainly have some unfavorable impact through elevated turbulence levels and mean upward velocities due to vertical redistribution 
of momentum. Although turbulent shear stresses and upward flow velocities in that region are one order smaller than inside the recirculation zone, it is expected that efficiency values presented in this study have a small, positive bias. They should be interpreted as an upper limit of silt curtain efficiency.

\section{Results}

Next, the LES model is used to generate an extensive dataset. Throughout the simulations, three parameters are varied, being the relative curtain height $h_{\text {rel }}$ (see equation 1 ), the velocity ratio $\theta$ (see equation $7, w_{s}$ denotes the settling velocity of the sediment particles) and the suspended sediment concentration profile at model inflow (see Figure 10), upstream of the silt curtain.

$$
\theta=\frac{w_{s}}{U}
$$

The range of tested parameter values is presented in Table 1 . The water depth is fixed, whereas the silt curtain height is varied. This choice does not constrain the validity of this study, as the flow field is controlled by the ratio of curtain height versus water depth. By varying $h_{s}$ and keeping $h$ fixed, the findings are valid for values of $h_{\text {rel }}$ between 0.25 and

0.75. Smaller values would lead to negligibly short silt curtains, whereas larger values do hardly occur in practice due to flaring of the curtain. Only with the application of very heavy weight chains, larger relative curtain heights are achievable, but this drastically increases the forces acting on the curtain with the risk of mechanical failure. Tested ambient flow velocities range between 0.05 and $0.5 \mathrm{~m} / \mathrm{s}$. The lower velocity represents very calm conditions, which are generally exceeded at dredging sites and in cases of silt curtain application (Jin et al., 
2003; Vu et al., 2010; Spearman et al., 2011; De Wit et al., 2014), whereas flow velocities larger than $0.5 \mathrm{~m} / \mathrm{s}$ also make silt curtains prone to mechanical failure (Francingues \& Palermo, 2005).

Note that sediment settling is parameterized directly through the settling velocity, instead of through defining a particle diameter. Equivalent particle diameters corresponding to the values of $w_{s}$ given in Table 1, assuming Stokes' law to apply to first order approximation, would range from $3 \mu \mathrm{m}$ to $100 \mu \mathrm{m}$. Because silt curtains are used as an environmental mitigation measure to reduce spreading of fine sediment, there is no need to treat larger settling velocities or particle diameters. The tested values of $w_{s}$ are sufficient to cover the range between very fine, persistent suspensions and flocculation conditions and are representative of suspended sediment properties in a dredge plume (Smith and Friedrichs, 2011).

The value of $C_{\max }$ is kept constant at $100 \mathrm{mg} / \mathrm{L}$, which assures negligible influence of sediment concentrations on fluid density and does not induce hindered settling. This choice implies that the total amount of sediment introduced in the model may vary between the various simulations, as the sediment flux into the domain varies with the flow velocity. Simulation times are long enough to reach stationary conditions, so that time-averaged concentrations remain stable. Turbulence-averaged parameters are obtained for steady state conditions only.

Panel A of Figure 11 shows values of $E_{S}$ at $10 h_{s}$ downstream of the silt curtain as a function of $h_{r e l}$ and $\theta$ for initially uniform concentration profile 1 (e.g. for $h_{r e l}=0.5, U=0.1 \mathrm{~m} / \mathrm{s}$, $w_{s}=1 \mathrm{~mm} / \mathrm{s}$ and $\theta=10^{-2}$, a value of $12 \%$ is found for $E_{S}$ at $\left.x=10 h_{s}\right) . E_{S}$ appears to be 
very sensitive to changes in the velocity ratio $\theta$. High settling velocities and low ambient flow velocities enhance the downward flux of suspended sediment between the upstream and downstream positions. A minor sensitivity of $E_{S}$ to $h_{r e l}$ is found. Increasing the silt curtain height has a slightly unfavorable influence on the gross efficiency. Only for fairly high values of $\theta$ (e.g. $w_{s}=5 \mathrm{~mm} / \mathrm{s}, U=10 \mathrm{~cm} / \mathrm{s}$ and $\theta=5 \cdot 10^{-2}$ ) significant reduction of $E_{s}$ is achieved. However, in most cases of silt curtain application, much lower settling velocities and higher ambient flow velocities are encountered (e.g. Jin et al., 2003 and Vu et al., 2010).

In panel B of Figure 11, values of $E_{\text {net }}$ are given for upstream concentration profile 1. All deviations with respect to panel A are attributed to the different choice of efficiency parameter, which now excludes the effect of undisturbed settling. The diagram of $E_{S}$ showed increasingly favorable values for high $\theta$, whereas this trend has completely vanished in the diagram of $E_{\text {net }}$. Apparently flow separation and associated turbulent mixing caused by the silt curtain has a stronger effect than the initial downward flux induced by the curtain. The favorable gross efficiency for high $\theta$ is completely caused by autonomous settling. For low velocity ratios, corresponding to relatively fine sediment and high ambient flow velocities, no significant difference is found between both efficiency parameters as undisturbed settling is not important. The slightly favorable efficiency percentages for low $h_{\text {rel }}$ around $\theta=10^{-2}$ are not sufficient to achieve a reasonable reduction of the environmental impact potential and are again constrained to rather exceptional values of $w_{s}$ and $U$.

Both right panels of Figure 11 present $E_{S}$ (panel C) and $E_{\text {net }}$ (panel D) for simulations with upstream concentration profile 2 (see Figure 10). As this profile contains all sediment in the upper half of the water column, curtain-induced turbulence may have a favorable influence 
through downward mixing of sediment. This favorable influence is indeed expressed by

371 positive and increasing efficiency parameters as $h_{\text {rel }}$ increases, while $\theta$ remains low. Silt

372 curtains blocking a bigger part of the water column induce more intense mixing. However, 373 again this favorable picture for $E_{S}$ completely vanishes if results are expressed in terms of

$E_{\text {net }}$, except for some negligibly small percentages $(<13 \%)$ in two regions of the diagram. Also for inflowing profiles of type 2, undisturbed settling leads to a higher efficiency than can be achieved with a silt curtain.

\section{Discussion}

Our results suggest that hanging silt curtains in a cross current cannot be effective in mitigating environmental impacts when assessed in a laterally homogeneous approach (i.e. effectively two-dimensional vertical), where horizontal diversion of currents around the curtain's edges is not possible. The downward flux of sediment induced by the curtain is compensated by intensified turbulent mixing. Such enhanced mixing will always occur when deploying a hanging silt curtain in ambient flow. At best, this leads to an approximately neutral effect of the silt curtain at high ambient flow velocities and low settling velocities of the sediment. Favorable settling conditions are obtained for low $U$ and high $w_{s}$. These conditions are controlled by rapid settling of the sediment. Silt curtains then have an explicitly unfavorable influence. Vu and Tan (2013) have concluded that the relative curtain height is one of the main parameters controlling the flow field around a silt curtain. They suggest that optimizing the curtain height might lead to favorable efficiency of a silt curtain. Based on the results presented in the previous sections, we endorse the big sensitivity of the flow field to 
the relative silt curtain height. However, evaluation of $E_{\text {net }}$ for the whole range of $\theta$ and $h_{\text {rel }}$ encountered in practice (panels B and D of Figure 11) leads to the conclusion that an optimal curtain height with favorable silt curtain efficiency does not exist. These findings do absolutely not imply that doing nothing is a viable strategy, as this may result in a significant environmental impact at some distance of a dredging site. PIANC (2010) have promoted the use of adaptive management strategies for environmental mitigation to cope with the sitespecific and unpredictable nature of dredging projects.

In reality, silt curtains have a finite width, and the flow can pass around their edges. Possible configurations in the horizontal plane have been shown in Figure 2. When applied in an open configuration (i.e. (a) in Figure 2), lateral boundaries are absent. Hence a three-dimensional flow field will develop, consisting of both vertical flow diversion (passing underneath) and horizontal flow diversion (passing around the edges). However, vertical diversion of the sediment-laden flow is still the intended working principle of a silt curtain. If the current is diverted horizontally, part of the suspended sediment will leak away without being brought closer to the bed by the curtain. Furthermore, additional flow separation and turbulent mixing is induced in the horizontal plane. Hence, the possibility of horizontal diversion is expected to result in decreased efficiency of hanging silt curtains. The question remains which portion of upstream suspended sediment will be diverted horizontally. Radermacher et al. (2013) have used two-dimensional horizontal (2DH) model simulations to assess the distribution of the upstream water discharge over vertical and horizontal diversion, incorporating the silt curtain as an internal discharge condition. For realistic values of $F$ and relative curtain width $W_{\text {rel }}$ (i.e. $F$ larger than 0.01 and $W_{\text {rel }}$, being the curtain width divided by the water depth, smaller than 100), they found that the fraction of the upstream discharge being diverted around the 
edges of the curtain is about equal to the relative curtain height. A silt curtain covering $60 \%$ of the water column causes about $60 \%$ of the upstream water to pass the curtain around its edges and about $40 \%$ to pass underneath the curtain. Although their 2DH, Reynolds-averaged modeling approach and assessment of discharges rather than sediment fluxes has its limitations, the results of Radermacher et al. (2013) can be used as a first order approximation of the effect of horizontal diversion. As a result, the efficiency percentages derived from Figure 11 are expected to be an upper limit, applying to the most favorable case of an infinitely wide silt curtain without horizontal diversion. Furthermore, these results imply that deployment of silt curtains with high values of $h_{\text {rel }}$ (or even covering the full water depth, such as the standing silt curtains that were mentioned in the introduction) leads to strong horizontal diversion of the flow, leaving the vertical distribution of suspended sediment in the water column largely untouched. If the curtain would be used in the near vicinity of the sensitive receptor, horizontal diversion may have a favorable effect by guiding suspended sediment away from the sensitive environment. However, in that case, partial vertical diversion and horizontal mixing through lateral shear downstream of the edges of the curtain will decrease silt curtain efficiency. The creation of a (spatially limited) calm zone just upstream of the curtain in case of large horizontal diversion might be another potential working mechanism of hanging silt curtains.

The influence of waves and wind-driven currents has been omitted in this study. Unlike currents, waves do not have the potential to transport suspended sediment over considerable distances. Their influence is therefore limited to potential destabilization of the curtain, enhancing curtain-induced turbulence. Wind-driven currents would produce an upstream flow profile different from the logarithmic profile used here. If the current is fully developed, or if 
an additional forcing mechanism is present (e.g. tide, free surface gradient), the full discharge will still pass underneath the curtain. Strong vertical redistribution of momentum in the contracting and separating flow past the silt curtain makes the downstream flow field practically insensitive to the upstream velocity profile. The only exception would be the case of not fully developed, purely wind-driven currents, where the flow in the top layer might be compensated by a curtain-induced return current near the bed. It is stressed that additional forcing mechanisms, other than wind, are very often present in a marine or riverine environment.

The sediment concentration profiles that were used in the numerical model simulations as an upstream boundary condition are highly schematic. Several other profiles have been tested in this study as well, including profiles which vary linearly over depth, and an empirical Rouselike profile corresponding to suspended fine sediment in equilibrium conditions (Whitehouse et al. 2000). However, concentration profiles encountered near a silt curtain are usually still fairly close to the source of suspended sediment. The range of realistic profiles is therefore very wide and is not constricted to equilibrium conditions. The two profiles presented in this paper can be thought to represent the two extreme cases that might potentially yield favorable silt curtain efficiency. Profile 1 has no vertical gradients and therefore allows a minimum amount of curtain-induced diffusion. Profile 2 contains all suspended sediment near the free surface, where it contributes maximally to the environmental impact potential $(P)$. Sediment can only be transported to a lower level in the water column, which by definition leads to a decrease in $P$. Hence, this provides an opportunity to the silt curtain to achieve favorable efficiency by vertical mixing. However, net silt curtain efficiency is still unfavorable for profiles 1 and 2, which further supports the conclusions drawn from this study. 
461 Furthermore, we have used a single sediment fraction, i.e. a single value of $w_{s}$ that applies to

462 a single model simulation. We have limited our study to conditions which do not involve

463 hindered settling (see e.g. Whitehouse et al., 2000), so non-linear interactions between

464 different sediment fractions can be neglected. As a result, the effect of multiple sediment

465 fractions can be determined by evaluating the efficiency parameters separately for every 466 fraction.

467 One aspect that has not been mentioned before is the increase in bed shear stresses caused by 468 a hanging silt curtain, induced by high near-bed velocities and increased turbulence 469 intensities. It is expected that this would enhance erosion of the bed, adding to the turbidity in 470 the water column and reducing the curtain's efficiency even further. However, this is only an 471 initial effect, as a new equilibrium between enhanced bed shear stresses and bed stability will 472 develop.

\section{Conclusions}

475 We have modeled the efficiency of hanging silt curtains, considering vertical diversion of the sediment-laden current to be the main working principle. Use was made of Large Eddy

477 Simulation to compute efficiency percentages in a two-dimensional vertical framework with 478 the silt curtain spanning the full width of the model. Validation of the numerical model was 479 done by means of laboratory experiments. The LES model was shown to be capable of accurately predicting vertical diversion of flow past a hanging silt curtain, in terms of timeaveraged flow velocities and turbulence parameters. The tested range of relevant input

482 parameter values was selected to be representative of typical cases of silt curtain application. 
In order to compute the efficiency, a new parameter was introduced. The commonly used gross efficiency parameter cannot be a suitable measure in case of favorable settling conditions (low ambient flow velocity and high settling velocity). Instead, we propose a net efficiency parameter, which compares silt curtain performance to a reference situation without such a curtain. The region over which silt curtain efficiency is evaluated ranges from upstream of the curtain to well beyond the recirculation zone at the downstream side, which approximately captures the region over which the fluid flow is affected by the presence of the silt curtain. Hanging silt curtains were shown to be an ineffective environmental measure for mitigation of suspended sediment concentrations when applied in cross-flow. An initial, downward flux of sediment is induced by the silt curtain, but is counteracted by curtaininduced flow separation and associated increased turbulent mixing. In case of favorable settling conditions, undisturbed settling of the sediment without a silt curtain is more effective than settling with a silt curtain in place. Thus under such conditions, the use of silt curtains leads to a larger environmental impact around a dredging site than without a silt curtain. In case of unfavorable settling conditions (high ambient flow velocity and low settling velocity), the silt curtain hardly has an influence. The height of the silt curtain relative to the water depth determines the amount of disturbance of the flow. A relatively deep curtain, blocking a larger part of the water column, leads to stronger turbulent mixing. Generally this yields unfavorable effects. Only when the sediment concentration profile at the upstream side of a silt curtain is biased towards the upper half of the water column and settling conditions are favorable, a higher silt curtain may lead to a slightly more favorable, but still negligible efficiency. In summary, no possibilities for efficiently applying a hanging silt curtain in crossflow were found, considering vertical diversion of the sediment-laden current to be the main working principle. 
507 It should however be noted that doing nothing is not a viable alternative for silt curtain

508 application. Decisions on mitigation of possible environmental impact should always be based 509 on a site-specific analysis, taking into account the local variability of environmental 510 conditions and the dredging activities concerned.

511 It is recommended to use the findings presented in this paper to optimize the design of future

512 field experiments with respect to silt curtain efficiency. Although the processes governing silt 513 curtain efficiency have been studied extensively in a numerical modeling environment, it is 514 important that these processes are identified and quantified in the field as well. Furthermore, 515 this will yield more insight in possible complicating factors like wave motions and wind516 driven currents.

\section{Acknowledgements}

519 This research was initiated and partly facilitated by dredging company Boskalis, in particular 520 by Fokko van der Goot, Stefan Aarninkhof, Gerard Hoogewerff and Karoune Nipius. They 521 are greatly acknowledged for backing up the simulation results with field experience and 522 knowledge on marine ecology. Svasek Hydraulics is acknowledged for its share in the 523 numerical model simulations. Finally, the laboratory staff of the TU Delft Laboratory for 524 Fluid Mechanics is thanked for facilitating the physical model study.

$527 C=$ Suspended sediment concentration $\left[\mathrm{kg} / \mathrm{m}^{3}\right]$; 
$528 C_{\max }=$ Maximum $C$ in upstream domain $\left[\mathrm{kg} / \mathrm{m}^{3}\right]$;

$529 C_{s}=$ Constant in sub-grid model $\left[\mathrm{kg} / \mathrm{m}^{3}\right]$;

$530 \quad C_{*}=$ Dimensionless $C[-]$;

$531 E_{n e t}=\quad$ Net silt curtain efficiency [\%];

$532 \quad E_{S}=\quad$ Gross silt curtain efficiency [\%];

$533 E_{\text {ref }}=$ Reference efficiency [\%];

$534 E_{z z}=$ Spectral density of turbulent kinetic energy $\left[\mathrm{m}^{2} / \mathrm{s}^{2} / \mathrm{Hz}\right]$;

$535 \quad F=$ Froude number [-];

$536 P=$ Environmental impact potential [-];

$537 \quad P_{\text {in }}=\quad P$ at inflow boundary $[-]$;

$538 P_{\text {ref }}=\quad P$ in reference situation [-];

$539 R=$ Reynolds number [-];

540 Sc $=$ Turbulent Prandtl-Schmidt number [-];

$541 U=$ Depth-averaged flow velocity $[\mathrm{m} / \mathrm{s}]$;

$542 W_{\text {rel }}=$ Relative silt curtain width $[\mathrm{m} / \mathrm{s}]$;

$543 \quad=\quad$ Frequency $\left[\mathrm{s}^{-1}\right]$;

544 f $=$ Acceleration vector due to body forces $\left[\mathrm{m} / \mathrm{s}^{2}\right]$;

$545 g=$ Gravitational acceleration $\left[\mathrm{m} / \mathrm{s}^{2}\right]$;

$546 h=\quad$ Water depth $[\mathrm{m}]$;

$547 \quad h_{\text {rel }}=$ Relative silt curtain height [-]; 


\begin{tabular}{|c|c|c|c|}
\hline 548 & $h_{\mathrm{s}}$ & $=$ & Silt curtain height $[\mathrm{m}]$; \\
\hline 549 & $p$ & $=$ & Pressure $\left[\mathrm{kg} /\left(\mathrm{s}^{2} \mathrm{~m}\right)\right]$; \\
\hline 550 & $r_{u}$ & $=$ & Turbulence intensity of u-velocity [m/s]; \\
\hline 551 & $r_{w}$ & $=$ & Turbulence intensity of w-velocity [m/s]; \\
\hline 552 & $t$ & $=$ & Time $[\mathrm{s}]$ \\
\hline 553 & $\mathbf{u}$ & $=$ & Velocity vector $[\mathrm{m} / \mathrm{s}]$; \\
\hline 554 & $\bar{u}$ & $=$ & Time-averaged velocity in $\mathrm{x}$-direction $[\mathrm{m} / \mathrm{s}]$; \\
\hline 555 & $\bar{w}$ & $=$ & Time-averaged velocity in z-direction [m/s]; \\
\hline 556 & $w_{s}$ & $=$ & Settling velocity $[\mathrm{m} / \mathrm{s}]$; \\
\hline 557 & $x$ & $=$ & x-coordinate $[\mathrm{m}]$; \\
\hline 558 & $y$ & $=$ & y-coordinate $[\mathrm{m}]$; \\
\hline 559 & $z$ & $=$ & z-coordinate $[\mathrm{m} / \mathrm{s}]$; \\
\hline 560 & $Z_{*}$ & $=$ & Dimensionless z-coordinate [-]; \\
\hline 561 & $\Gamma$ & $=$ & Diffusion coefficient $\left[\mathrm{m}^{2} / \mathrm{s}\right]$; \\
\hline 562 & $\theta$ & $=$ & Velocity ratio [-]; \\
\hline 563 & $v$ & $=$ & Kinematic viscosity $\left[\mathrm{m}^{2} / \mathrm{s}\right]$; \\
\hline 564 & $v_{e}$ & $=$ & Eddy viscosit $\left[\mathrm{m}^{2} / \mathrm{s}\right] ;$ \\
\hline 565 & $v_{\text {mol }}$ & $=$ & Molecular viscosity $\left[\mathrm{m}^{2} / \mathrm{s}\right]$; \\
\hline 566 & $v_{\text {sgs }}$ & $=$ & Sub-grid-scale viscosity $\left[\mathrm{m}^{2} / \mathrm{s}\right]$; \\
\hline 567 & $v_{t}$ & $=$ & Turbulent viscosity $\left[\mathrm{m}^{2} / \mathrm{s}\right]$; \\
\hline
\end{tabular}


$568 \rho=$ Density $\left[\mathrm{kg} / \mathrm{m}^{3}\right]$;

$569 \quad \rho_{s}=$ Sediment density $\left[\mathrm{kg} / \mathrm{m}^{3}\right]$;

$570 \quad \rho_{a}=$ Ambient water density $\left[\mathrm{kg} / \mathrm{m}^{3}\right]$;

$571 \tau=$ Shear stress tensor $\left[\mathrm{kg} /\left(\mathrm{s}^{2} \mathrm{~m}\right)\right]$; and

$572 \tau_{u w}=$ Reynolds shear stress in the $\mathrm{x}-\mathrm{z}$ plane $\left[\mathrm{kg} /\left(\mathrm{s}^{2} \mathrm{~m}\right)\right]$.

574 References

575 Antonopoulos-Domis M. (1981). "Large-eddy simulation of a passive scalar in isotropic 576 turbulence.” Journal of Fluid Mechanics, 104, 55-79.

577 Bray R.N. - editor (2008). Environmental aspects of dredging, Taylor \& Francis, Leiden, 578 Netherlands.

579 Erftemeijer P.L.A. and R.R. Robin Lewis (2006). "Environmental impacts of dredging on 580 seagrasses: a review.” Marine Pollution Bulletin, 52(12), 1553-1572.

581 Erftemeijer P.L.A., B. Riegl, B.W. Hoeksema and P.A. Todd (2012). "Environmental impact 582 of dredging and other sediment disturbances on corals: a review.” Marine Pollution Bulletin, $58364(9), 1737-1765$.

584 Fadlun, E., Verzicco, R., Orlandi, P., Mohd-Yusof, J. (2000). “Combined immersed-boundary 585 finite-difference methods for three-dimensional complex flow simulations.” Journal of 586 Computational Physics, 161(1), 35-60.

587 Francingues N.R. and M.R. Palermo (2005). "Silt curtains as a dredging project management 588 practice.” DOER Technical Notes Collection (ERDC TN-DOER-E21), U.S. Army Engineer 589 Research and Development Center, Vicksburg, USA. 
590

591

592

593

594

595

596

597

598

599

600

601

602

603

604

605

606

607

608

609

610

611

612

Jarrin, N., S. Benhamadouche, D. Laurence and R. Prosser (2006). “A synthetic-eddy-method for generating inflow conditions for large-eddy simulations." International Journal of Heat and Fluid Flow, 27(4), 585-593.

JBF Scientific Corporation (1978). “An analysis of the functional capabilities and performance of silt curtains.” Technical Report D-78-39, U.S. Army Engineer Waterways Experiment Station, Vicksburg, USA.

Jin J.Y., J.W. Chae, W.O. Song, J.S. Park, S.E. Kim, W.M. Jeong, K.D. Kum and J.K. Oh (2003). "Behavior of currents and suspended sediments around a silt screen.” Ocean and Polar Research, 25(3S), 399-408.

Kraichnan R.H. and D. Montgomery (1980). “Two-dimensional turbulence.” Reports on Progress in Physics, 43, 547-619.

Manninen, M., Taivassalo, V., Kallio, S. (1996). “On the mixture model dredger: the effect of dredging speed, propeller, overflow location for multiphase flow.” VTT publications 288, Technical Research Center of Finland.

Nicoud, F. and F. Ducros (1999). "Subgrid-scale stress modeling based on the square of the velocity tensor.” Flow, turbulence and combustion, 62, 183-200.

Ogilvie J.C., D. Middlemiss, M.W. Lee, N. Crossouard and N. Feates (2012). “Silt curtains a review of their role in dredging projects.” Proc., CEDA Dredging Days, Abu Dhabi, UAE.

PIANC (2010). “Dredging and port construction around coral reefs.” PIANC report no. 108 2010.

Pope, S.B. (2000). Turbulent Flows, Cambridge University Press, Cambridge, UK.

Radermacher M., F. van der Goot, D.C. Rijks and L. de Wit (2013). “The art of screening: efficiency of silt screens.” Proc., World Dredging Congress XX, Brussels, Belgium. 
613 Smith, S.J. and C.T. Friedrichs (2011). "Size and settling velocities of cohesive flocs and 614 suspended sediment aggregates in a trailing suction hopper dredge plume.” Continental Shelf 615 Research, 31(10), S50-S63.

616 Spearman, J., A. de Heer, S. Aarninkhof and M. van Koningsveld (2011). "Validation of the 617 TASS system for predicting the environmental effects of trailing suction hopper dredgers.” 618 Terra et Aqua, 125, 14-22.

619 Van Prooijen, B.C. and J.C. Winterwerp (2010). “A stochastic formulation for erosion of 620 cohesive sediments.” Journal of Geophysical Research, 115(C1), C01005.

621 Vu, T.T. and S.K. Tan (2010). "Laboratory investigation of hydraulic performance of silt 622 screens.” Proc., $9^{\text {th }}$ International Conference on Hydrodynamics, Shanghai, China.

623 Vu, T.T., S.K. Tan and S. Doorn-Groen (2010). “A case study of silt screen performance.” 624 Proc., World Dredging Congress XIX, Beijing, China.

625 Vu, T.T. and S.K. Tan (2013). "Velocity and turbulence characteristics around a silt screen.” 626 Maritime Engineering, 166(2), 89-97.

627 Wang, H., F. Si, G. Lou, W. Yang and G. Yu (2015). "Hydrodynamic characteristics of a 628 suspended curtain for sediment trapping.” Journal of Waterway, Port, Coastal and Ocean 629 Engineering, 141(1), 04014030.

630 Whitehouse, R.J.S., R.L. Soulsby, W. Roberts and H.J. Mitchener (2000). Dynamics of 631 estuarine muds, Thomas Telford Publishing, London, UK.

632 Wit, L. de and C. van Rhee (2012). “Testing different advection schemes for coarse high Re 633 LES simulations of jet in crossflow and coflow." Proc., $9^{\text {th }}$ International ERCOFTAC 634 Symposium on Engineering Turbulence Modelling and Measurements, Thessaloniki, Greece.

635 Wit, L. de, A.M. Talmon and C. van Rhee (2014). “3D CFD simulations of trailing suction 636 hopper dredger plume mixing: Comparison with field measurements.” Marine Pollution 637 Bulletin, 88, 34-46. 
638 Wit, L. de (2015). 3D CFD modelling of overflow dredging plumes, PhD thesis, Delft 639 University of Technology.

640 Yasui A., I. Deguchi and M. Ono (1999). "Performance of silt protector in three dimensional 641 flow.” Proc., Ninth International Offshore and Polar Engineering Conference, Brest, France.

\section{Appendix. Numerical model description}

643 In the CFD model the Navier Stokes equations with variable density are solved, see Equations $644 \quad 8$ and 9.

$$
\begin{gathered}
\frac{\partial \rho}{\partial t}+\nabla \cdot(\rho \mathbf{u})=0 \\
\frac{\partial \rho \mathbf{u}}{\partial t}+\nabla \cdot(\rho \mathbf{u u})=-\nabla p+\nabla \cdot \boldsymbol{\tau}+\rho \mathbf{f}
\end{gathered}
$$

647 where $\rho$ is the density, $\mathbf{u}$ is the velocity vector, $p$ is the pressure, $\boldsymbol{\tau}$ is a shear stress tensor 648 and $\mathbf{f}$ is the acceleration vector due to body forces. The shear stress tensor $649 \boldsymbol{\tau}=v_{e}\left(\nabla \mathbf{u}+\nabla \mathbf{u}^{T}-2 / 3 \nabla \cdot \mathbf{u}\right)$ contains a contribution from molecular and turbulent viscosity 650 by the eddy viscosity concept: $v_{e}=v_{\text {mol }}+v_{t}$. Turbulence is modelled using the LES approach 651 in which a spatial filter equal to the mesh size is applied to the flow field and a turbulence 652 model is used for the sub-grid-scale contribution: $v_{t}=v_{s g s}$. This sub-grid-scale viscosity is 653 determined by the WALE model (Nicoud and Ducros 1999) with Smagorinksy constant $654 C_{s}=0.325$. The sediment volume concentration $C$ is resolved with Equation 10 .

$$
\frac{\partial C}{\partial t}+\nabla \cdot(\mathbf{u} C)=\nabla \cdot(\Gamma \nabla C)
$$


with the diffusion coefficient $\Gamma=v_{e} / \sigma_{T}$ and a turbulent Prandtl-Schmidt number $S c=0.5$.

657 The density $\rho$ is obtained from the sediment concentration by Equation 11 .

658

$$
\rho=\rho_{a}+\left(\rho_{s}-\rho_{a}\right) C
$$

659

660

661

662

663

664

665

666

667 Sediment particles settle with gravity with a vertical drift velocity superimposed on the CFD 668

669

670

where $\rho$ is the actual mixture density at each location in the grid, $\rho_{s}$ is the sediment density and $\rho_{a}$ is the ambient water density. A second order (time and space) parallel (domain decomposition) finite volume method is used on a staggered mesh. Advection of momentum is carried out with a low dissipation artificial viscosity scheme AV6 to prevent wiggles in front of the silt curtain (De Wit and Van Rhee 2012). Advection of sediment concentration is carried out with a Total Variation Diminishing (TVD) scheme with the Van Leer limiter to prevent non-physical negative concentrations. The silt curtain is implemented using a direct forcing Immersed Boundary Method (Fadlun et al. 2000).

flow velocity (Manninen et al. 1996). At the bed, sediment particles deposit with the settling velocity. Erosion from the bed of previously deposited sediment is not accounted for in the simulations. For more details about the CFD model, see De Wit (2015). 
672 Table 1. Ranges of tested parameter values in the numerical model.

673

\begin{tabular}{ll}
\hline Parameter & Range \\
\hline $\mathrm{U}$ & $0.05-0.5[\mathrm{~m} / \mathrm{s}]$ \\
$\mathrm{w}_{\mathrm{s}}$ & $0.01-10[\mathrm{~mm} / \mathrm{s}]$ \\
$\mathrm{h}_{\mathrm{s}}$ & $1.25-3.75[\mathrm{~m}]$ \\
$\mathrm{H}$ & $5.0[\mathrm{~m}]$
\end{tabular}

674

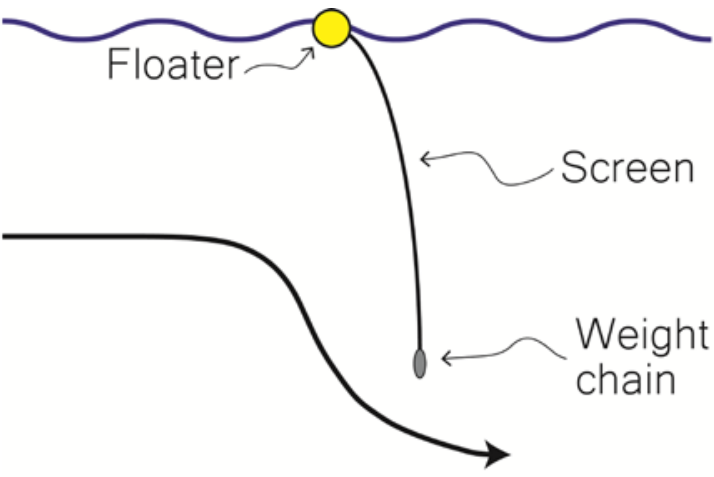

Hanging silt curtain

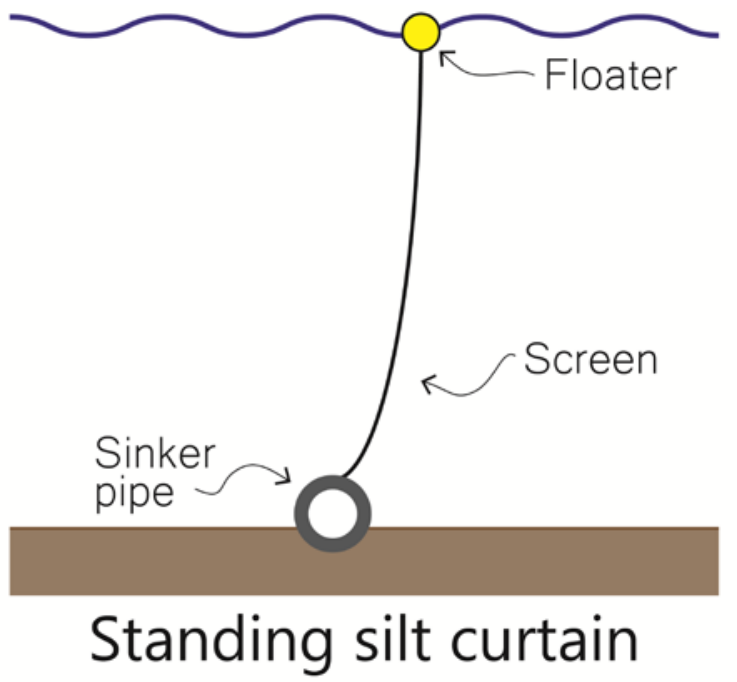

676 Fig. 1. Schematic cross-section of silt curtain types: hanging (left) and standing (right). 

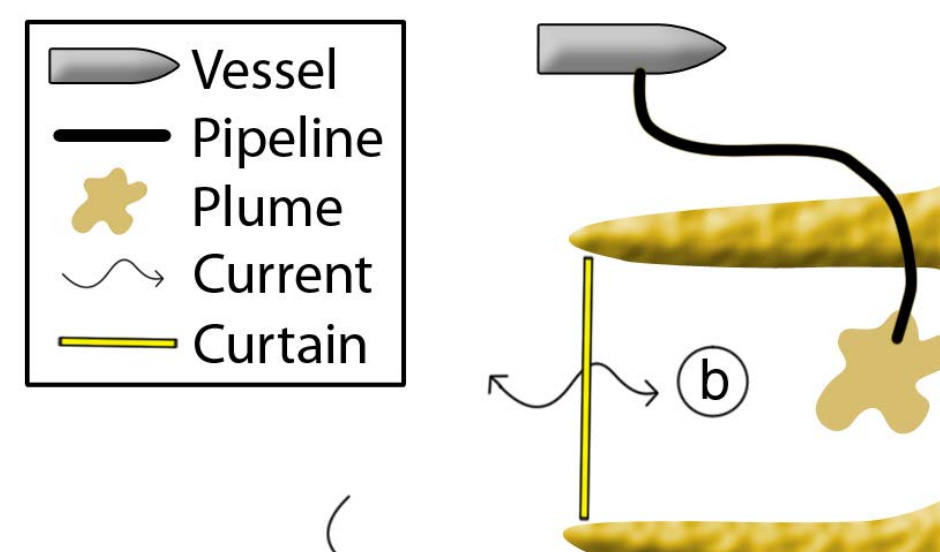

(a)

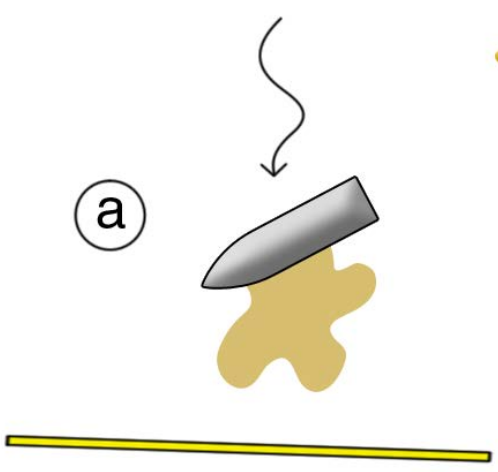

677

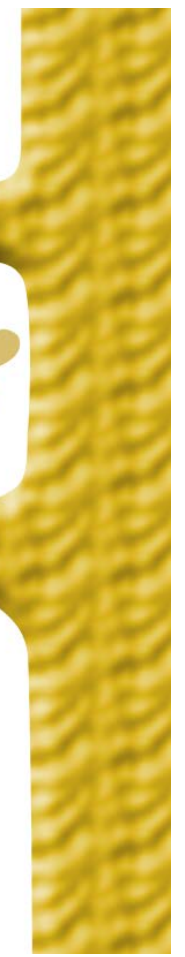

678

679

680

681

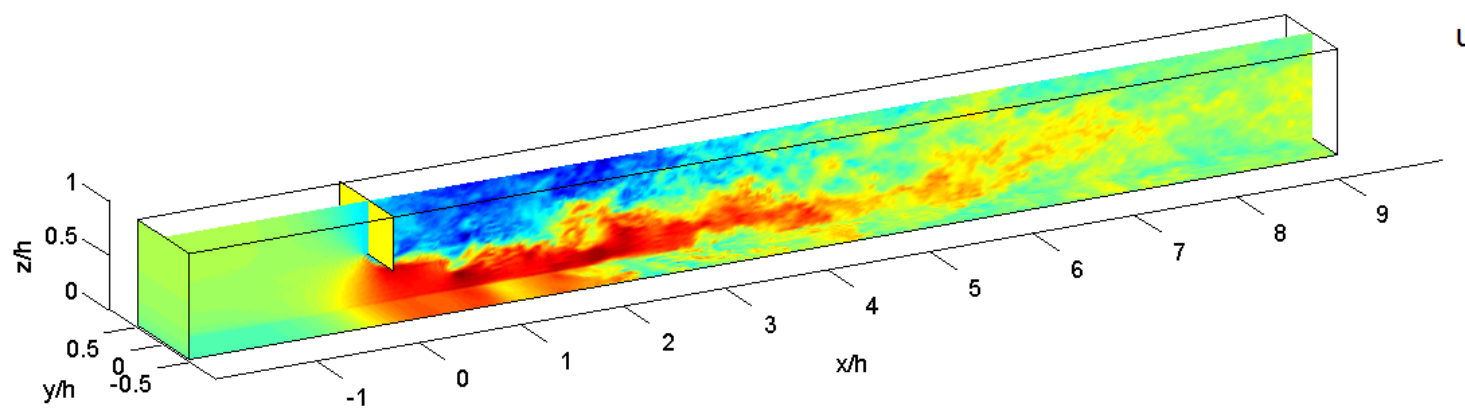

$\mathrm{u}(\mathrm{m} / \mathrm{s})$

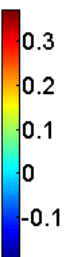

0.1

682 Fig. 3. Geometry of the numerical model domain. The hanging silt curtain is depicted as a

683 vertical plane at $x=0$. For simulations at laboratory scale, $h$ equals $0.35 \mathrm{~m}$, whereas this is 5 $684 \mathrm{~m}$ in real scale simulations. The nature of LES is clearly demonstrated by the turbulent eddies 685 present in the plot of horizontal velocities during an arbitrary simulation. 


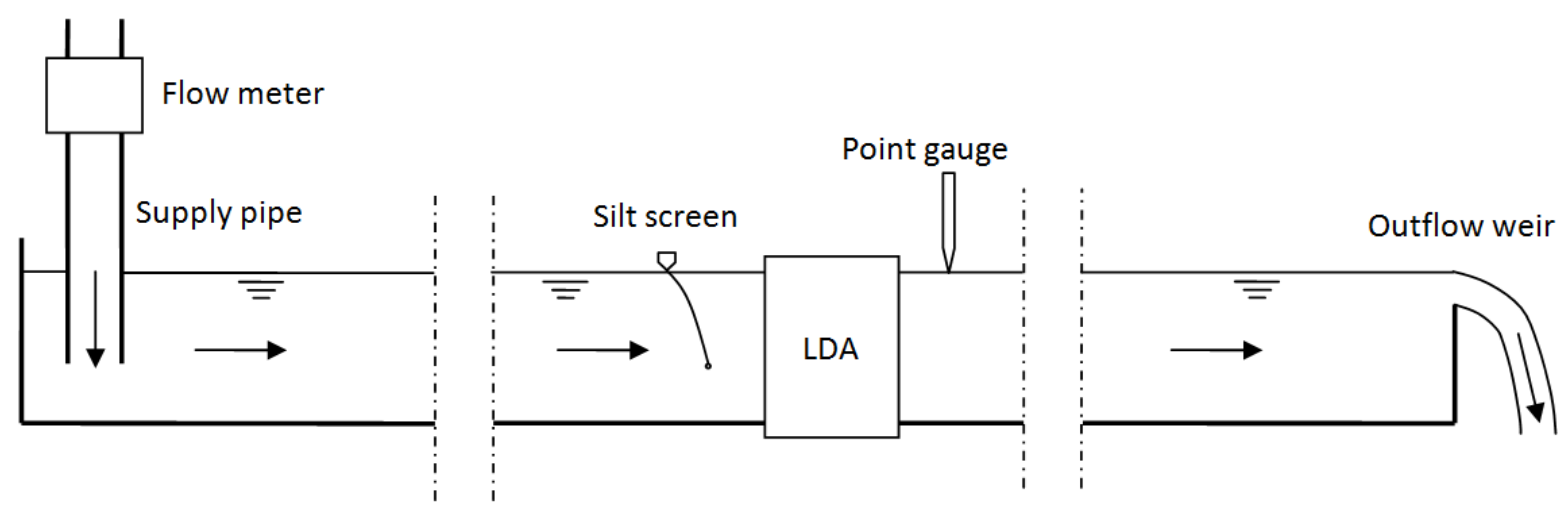

688 Fig. 4. Schematic diagram of the experimental setup in the laboratory flume with a total 689 length of $14 \mathrm{~m}$.

690

691

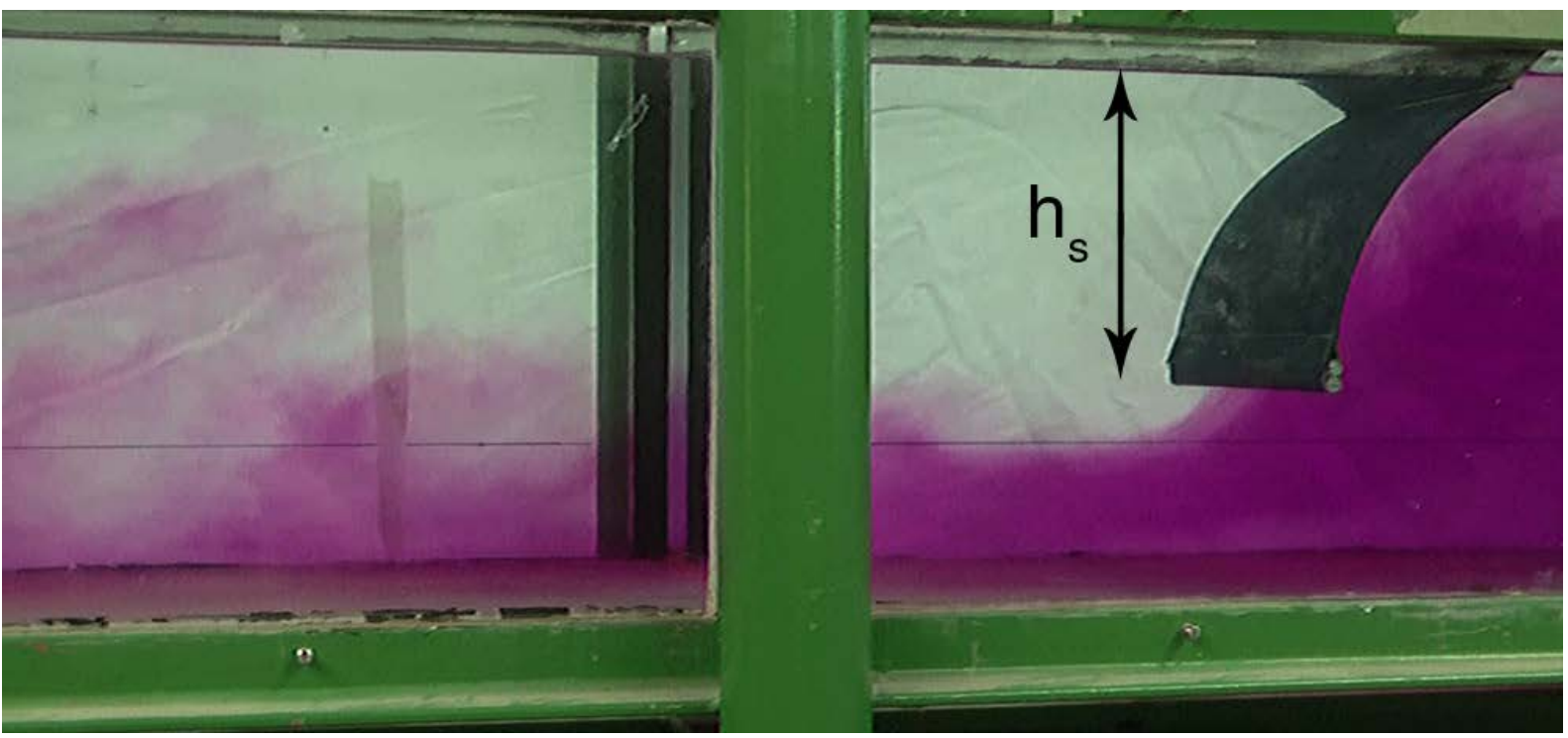

692 Fig. 5. Snapshot of a dye injection in the laboratory flume, during an experiment with

$693 F r=0.043$ and $h_{r e l}=0.75$ (before flaring). Image by Max Radermacher. 


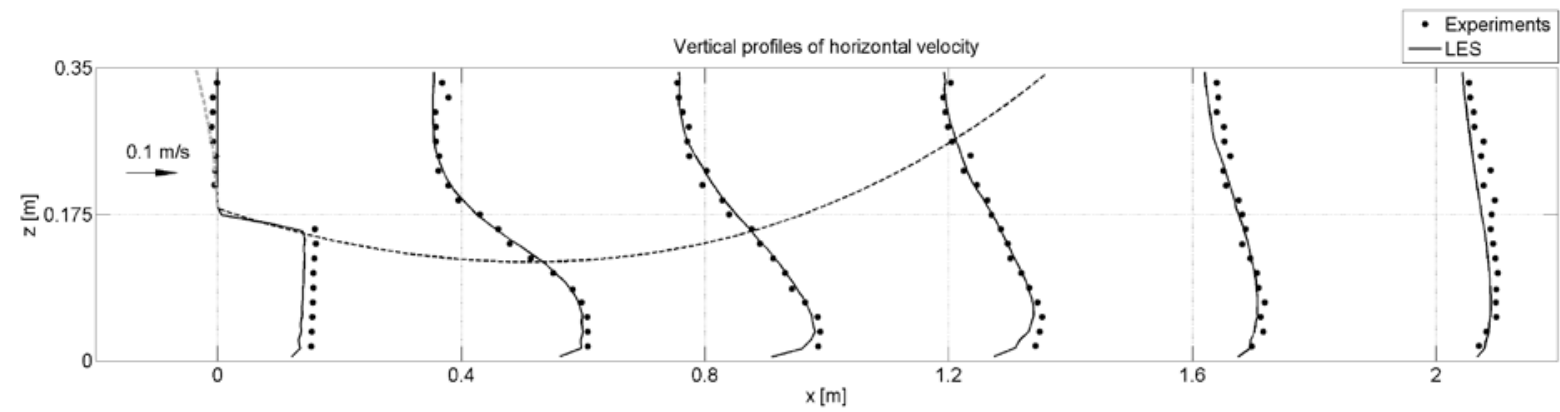

695

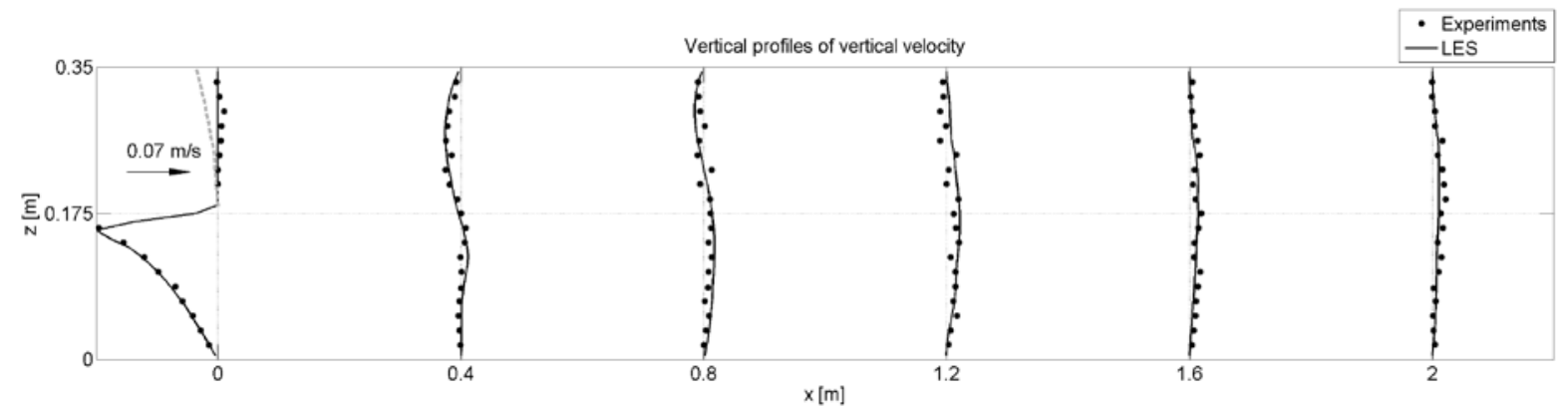

696 Fig. 6. Measured and computed time-averaged flow velocities $\bar{u}$ and $\bar{w}$. The laboratory

697 measurements are represented by dots, the LES results by solid lines. The arrow at the left

698 indicates the scale of the velocity axis at each vertical profile. The dashed gray line shows the

699 deformation of the silt curtain during the laboratory run. The approximate extent of the

700 recirculation zone in the wake of the silt curtain is indicated with a black dashed line in the 701 upper panel. 

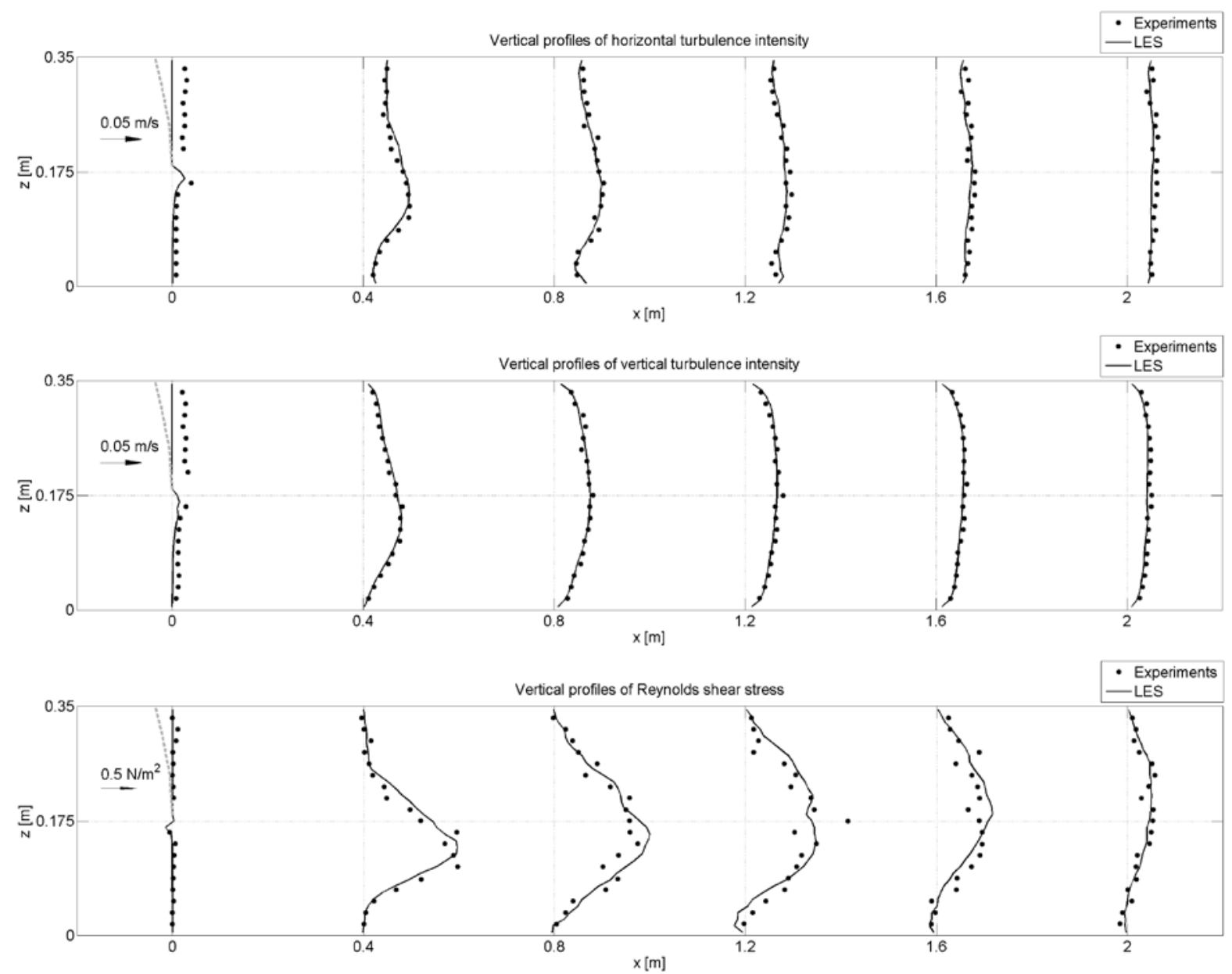
Reynolds shear stress $\tau_{u w}$. 


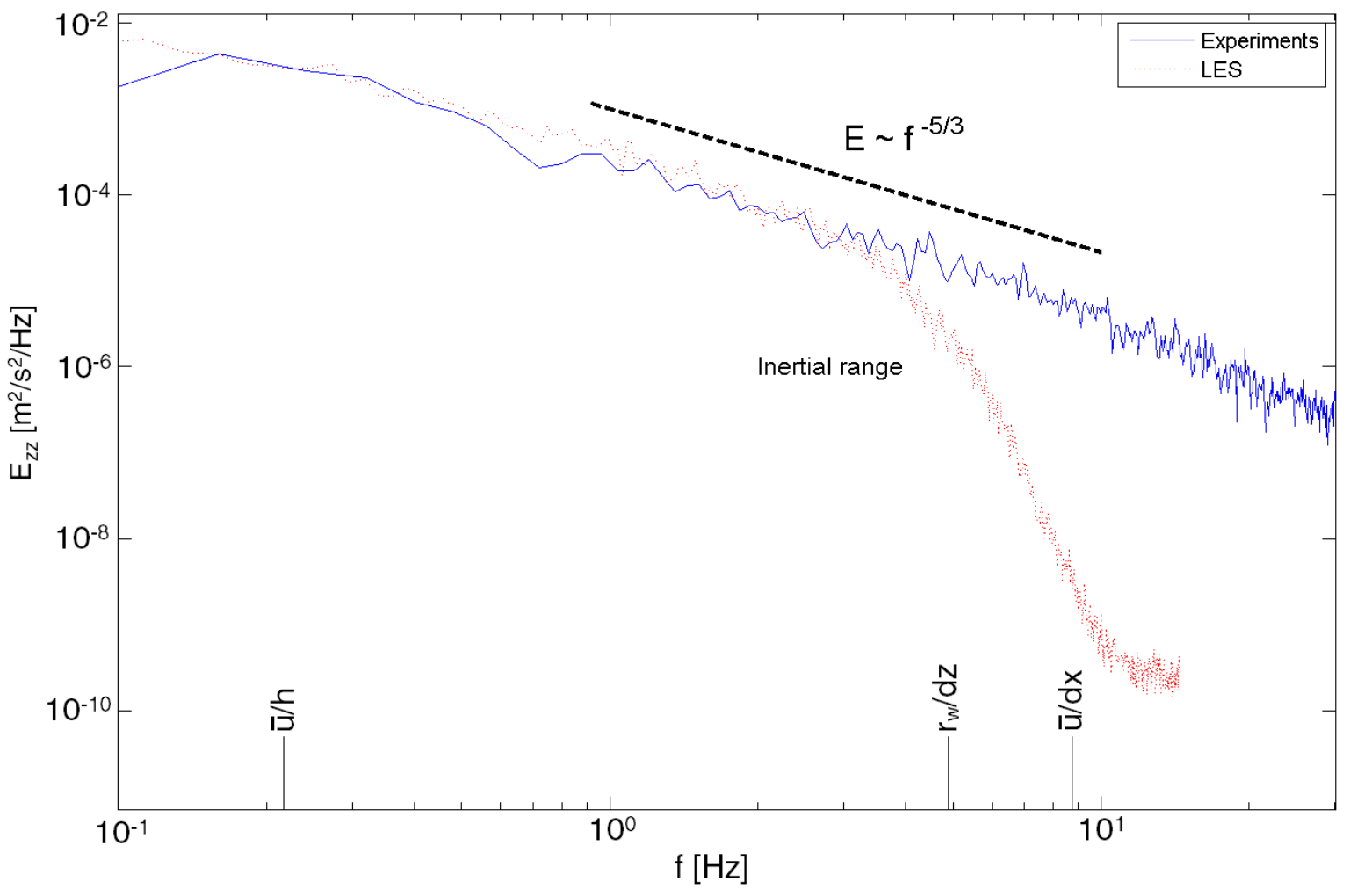

708 Fig. 8. Turbulent kinetic energy density spectra for a laboratory time series of vertical velocity $709 w$ and its numerical counterpart. Several characteristic time scales are indicated along the 710 frequency axis: $\bar{u} / h$ is a measure for the lowest turbulent frequencies that can occur in the 711 model domain, whereas $\bar{u} / d x$ (with $d x$ the mesh size in $x$ direction) is a measure for the 712 highest turbulent frequencies that can be computed on the numerical grid and $r_{w} / d z$ is a 713 measure for the frequency where the sub-grid-stress model comes into play. 


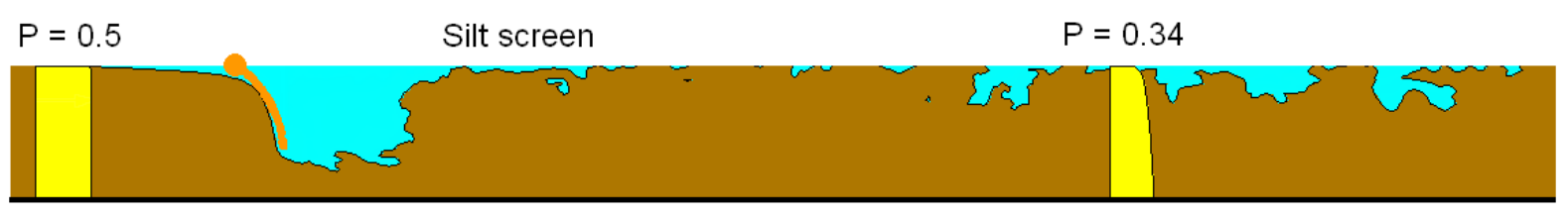
$P=0.5$
Reference situation
$P=0.29$

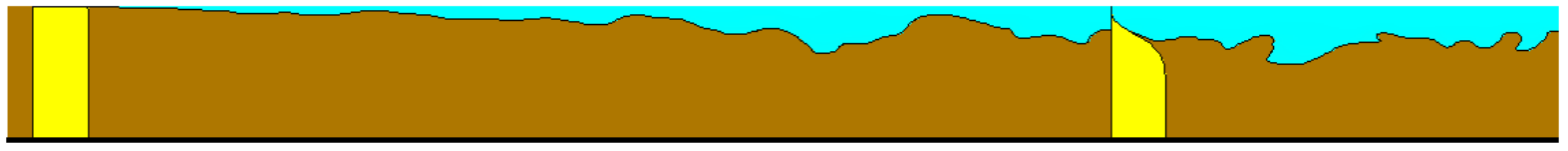

717 Fig. 9. Schematic example of vertical profiles of $C_{*} Z_{*}$ for a situation with and without a silt

718 curtain. The depth-integrated value (i.e. $P$ ) is indicated above each profile. In this particular

719 example, application of a silt curtain is unfavorable, as $E_{S}=32 \%$ and $E_{n e t}=-10 \%$, i.e. a

720 deterioration of turbidity levels.

721
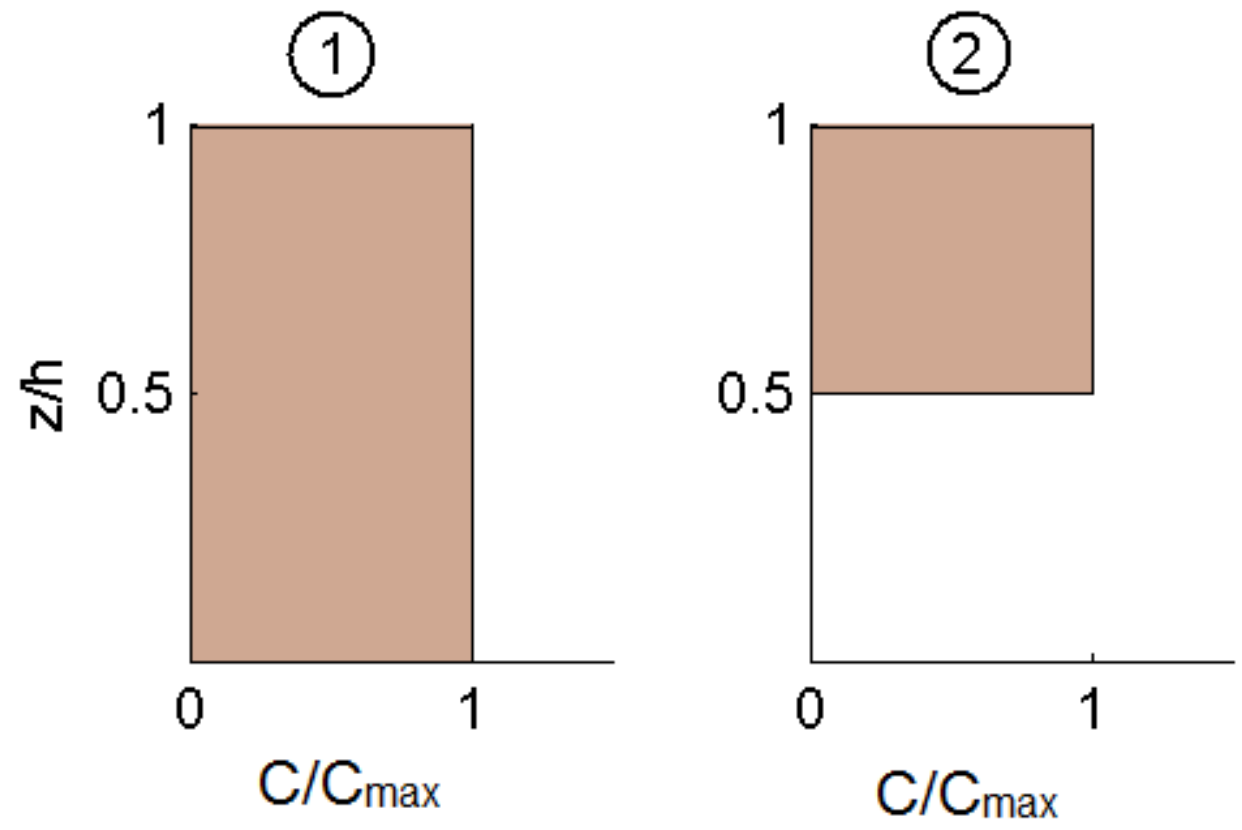

723 Fig. 10. Different concentration profiles 1 and 2 as applied at the upstream boundary in the numerical model simulations. 

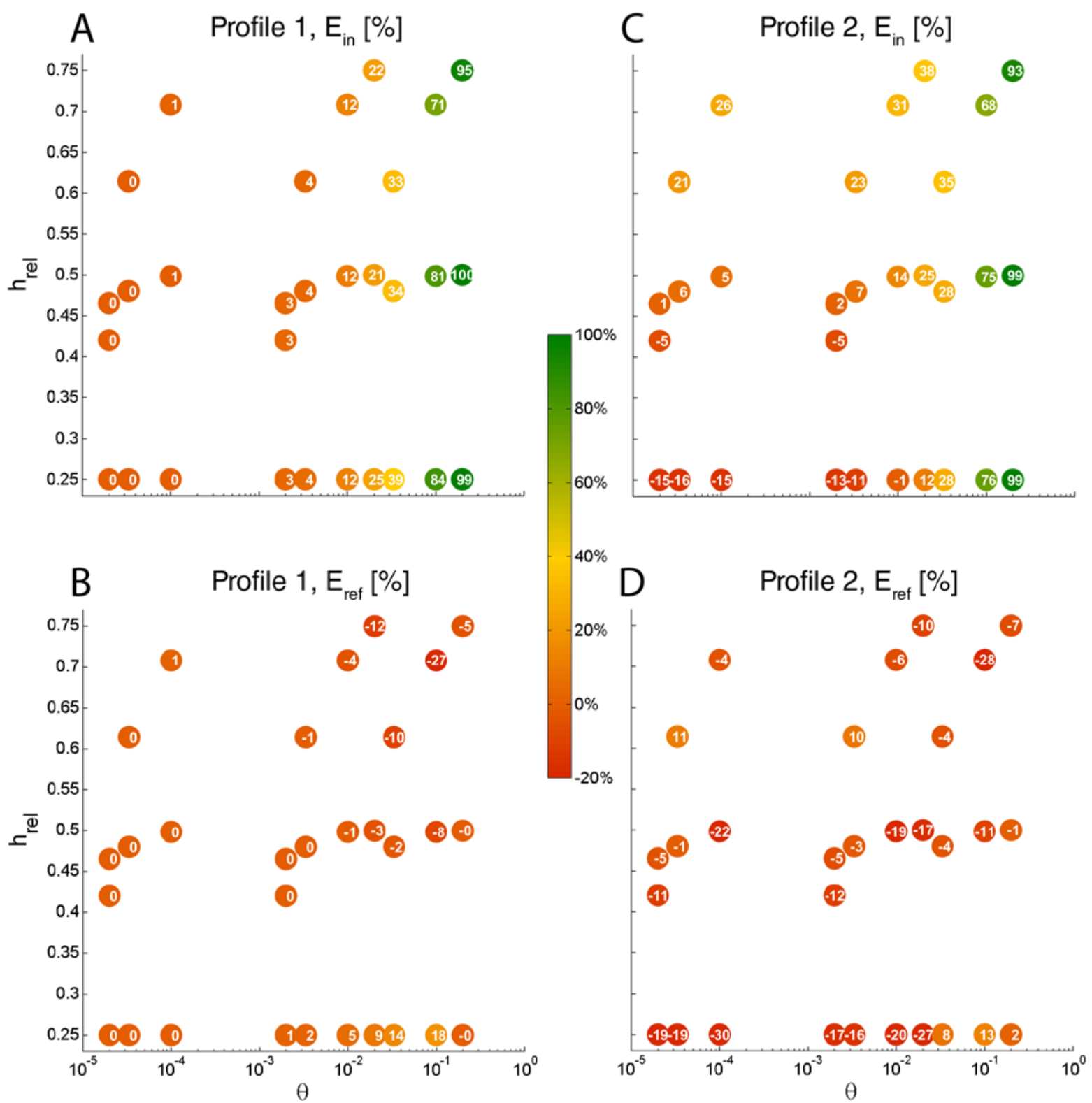

727 Fig. 11. Results of the numerical simulations as a function of $\theta$ and $h_{r e l}$. Coloured dots in the 728 upper panels (A \& C) represent inflow efficiency $E_{S}\left(10 h_{s}\right)$, those in the lower panels (B \& 729 D) represent $E_{n e t}\left(10 h_{s}\right)$. The results in the left panels (A \& B) are obtained from simulations 730 with inflow profile 1, those in the right panels (C \& D) are obtained from simulations with 731 inflow profile 2. The numbers in the dots show the exact efficiency percentage obtained from 732 every model simulation. 